\title{
High prevalence of low back pain among young basketball players with lower extremity pain: a cross-sectional study
}

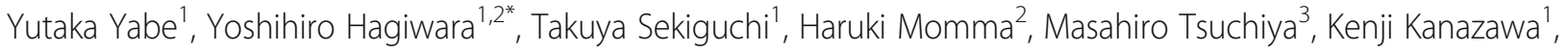
Nobuyuki Itaya ${ }^{1}$, Shinichirou Yoshida', Yasuhito Sogi ${ }^{1}$, Toshihisa Yano ${ }^{1}$, Takahiro Onoki ${ }^{1}$, Eiji Itoi ${ }^{1}$ and Ryoichi Nagatomi ${ }^{2,4}$

\begin{abstract}
Background: Low back pain (LBP) is a common problem among young basketball players in addition to lower extremity injuries. However, studies that focus on LBP with lower extremity pain are limited. From the perspective of the kinematic chain, disrupted lower extremity function can lead to LBP. The association between these two symptoms in basketball players, however, has not been reported. Therefore, this study aimed to clarify the association between lower extremity pain and LBP among young basketball players.

Methods: This cross-sectional study was conducted on school-aged basketball players $(n=592)$. Information regarding their sporting activities was collected using a self-reported questionnaire. Musculoskeletal pain such as low back, knee, and ankle pain was assessed. The sports players with knee and/or ankle pain were defined as having lower extremity pain. Multivariate logistic regression analysis was used to assess the association between lower extremity pain and LBP. Odds ratios (OR) and 95\% confidence intervals (95\% Cl) were calculated. The associations of knee or ankle pain with LBP were similarly assessed.

Results: School-aged basketball players had a point prevalence of $12.8 \%$ for LBP. Compared with the players without lower extremity pain, the players with lower extremity pain had higher rates of LBP, with an adjusted OR $(95 \% \mathrm{Cl})$ of 6.21 (3.57-10.80). There was also a significant association of knee and ankle pain with LBP. Compared with the players without knee or ankle pain, the adjusted ORs (95\% Cl) for LBP were $4.25(2.55-7.07)$ in the players with knee pain and $3.79(2.26-6.36)$ in the players with ankle pain.

Conclusions: Lower extremity pain was associated with LBP among school-aged basketball players. Further research is needed to clarify the mechanism of this association, which will provide useful information for prevention and treatment of LBP among young basketball players.
\end{abstract}

Keywords: Ankle pain, Basketball, Knee pain, Low back pain, Lower extremity pain, School-aged

\footnotetext{
*Correspondence: hagi@med.tohoku.ac.jp

'Department of Orthopaedic Surgery, Tohoku University School of Medicine,

1-1 Seiryo-machi, Aoba-ku, Sendai 980-8574, Japan

${ }^{2}$ Department of Medicine and Science in Sports and Exercise, Tohoku

University School of Medicine, 2-1 Seiryo-machi, Aoba-ku, Sendai 980-8575,

Japan

Full list of author information is available at the end of the article
}

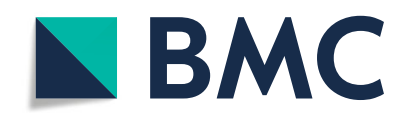

( The Author(s). 2020 Open Access This article is licensed under a Creative Commons Attribution 4.0 International License, which permits use, sharing, adaptation, distribution and reproduction in any medium or format, as long as you give appropriate credit to the original author(s) and the source, provide a link to the Creative Commons licence, and indicate if changes were made. The images or other third party material in this article are included in the article's Creative Commons licence, unless indicated otherwise in a credit line to the material. If material is not included in the article's Creative Commons licence and your intended use is not permitted by statutory regulation or exceeds the permitted use, you will need to obtain permission directly from the copyright holder. To view a copy of this licence, visit http://creativecommons.org/licenses/by/4.0/. The Creative Commons Public Domain Dedication waiver (http://creativecommons.org/publicdomain/zero/1.0/) applies to the data made available in this article, unless otherwise stated in a credit line to the data. 


\section{Background}

Low back pain (LBP) is a common problem among young sports players [1]. LBP negatively impacts athletic performance, and sometimes interferes with young sports players' continued participation in a sport [2]. Therefore, clarifying the factors related to LBP is necessary for the effective management of this problem in young sports players. Because different sports require specific postures that place a load on the low back, some sports have a higher prevalence of LBP [3].

Basketball is a major global sport with approximately 450 million players [4]. Basketball includes intensive movements, which can often lead to several injuries [5]. For example, injuries of the lower extremities, particularly the knees and ankles, are the most common injuries among basketball players [6]. Although little attention has been paid to LBP among basketball players; some authors report that basketball players have a high prevalence of LBP [3, 7]. Basketball involves a high frequency of jumps and landings with ball-handling [5, 8]. Furthermore, basketball includes rotational and asymmetrical movements [4]. These motions are considered to lead to high LBP rates among basketball players [7]. Although reports that have investigated factors related to LBP among basketball players are rare, generally, age [9], sex [8], body mass index (BMI) [7], and intensity/frequency of training [8] are thought to be related to LBP.

Recently, the kinematic chain has received increased attention from athletes because a disturbance in the kinematic chain is thought to cause sports injuries [10]. Furthermore, some reports have demonstrated correlations with other sports between pain in various body parts, such as low back and elbow pain, as well as neck and shoulder pain $[10,11]$, which are thought to arise from disrupted kinematic chains [12]. In addition, athletes with ligamentous laxity due to previous trauma of the lower extremities were reported to have a higher rate of LBP [12]. Forces transfer from the lower extremities through the trunk to the upper extremities during body motions [13] and thus we hypothesised that loss of function in the lower extremities due to pain may lead to LBP among basketball players. To prevent and treat LBP in basketball players, it may be useful to elucidate the associations of lower extremity pain with LBP. Nevertheless, there have been no reports evaluating these associations among basketball players. The present study therefore aimed to assess the association of lower extremity pain, such as knee and ankle pain, with LBP among school-aged basketball players.

\section{Methods}

\section{Participants}

This study forms one part of the comprehensive crosssectional study of young sports players (age, 6-15 years) belonging to teams registered in the amateur sports association in Miyagi prefecture, Japan [14]. The association includes a variety of sports teams and has registered 25,469 sports players. Information that related to sporting activity participation was assessed with a selfreported questionnaire (Additional file 1), which was mailed to all sports players along with an informed consent form in October 2014. Although participants were instructed to answer the questionnaires by themselves, parents were allowed to assist the younger participants.

\section{Low back and lower extremity pain}

The outcome of interest was LBP and the main predictor was lower extremity pain. Low back, knee, and ankle pain were evaluated by the self-reported questionnaire [14]. The question was "Do you have pain in any parts of your body now? If yes, please mark the parts where you have pain with a circle (multiple answers were allowed)." The body parts were illustrated with a diagram that included names. The participants with knee and/or ankle pain were defined as having lower extremity pain [15]..

\section{Covariates}

The following variables were assessed by the self-reported questionnaire and were included in the analysis as covariates because they were considered potential cofounding factors: sex (boy or girl), age, BMI: calculated using self-reported height and weight), team level (recreation, local competition, prefectural competition, Tohoku district competition, national competition), practice days per week, practice hours per day on weekdays and on weekends, participation frequency in games (never, seldom, sometimes, and often), and practice intensity (low-to-medium, high) [16].

\section{Statistical analysis}

Continuous variables were presented as medians with interquartile range (IQR) and categorical variables were presented as proportions and percentages (\%). The prevalence of low back and lower extremity pain was also presented as proportions and percentages (\%). Univariate and multivariate logistic regression analyses were examined to assess the associations of lower extremity pain with LBP, and odds ratios (ORs) and 95\% confidence intervals (95\% CIs) were calculated [17]. Furthermore, the association of knee or ankle pain with LBP was assessed in the same manner. SPSS 24.0 (SPSS Japan Inc., Tokyo, Japan) was used for the statistical analysis and values of $P<0.05$ were considered statistically significant.

\section{Results}

Among the 25,469 registered sports players, 7333 (28.8\%) replied to the questionnaire with consent to participate in this study before the end of December 2014. Of them, 680 sports players belonged to basketball teams. Respondents who had missing data were excluded $(n=88)$, and a final 
sample size of 592 young basketball players was included (Fig. 1). The participants' baseline characteristics are shown in Table 1 . The participants' median age was 13 (IQR: 12-14) years. The point prevalence of LBP, knee pain, and ankle pain among school-aged basketball players was 12.8\% (76/592), 25.2\% (149/592), and 21.5\% (127/ 592), respectively. Defined lower extremity pain was found in $36.7 \%$ (217/592) of the participants. There was a significant association between lower extremity pain and LBP. Compared with the participants without lower extremity pain, those with lower extremity pain had higher rates of LBP, and the adjusted OR (95\% CI) was $6.21(3.57-10.80)$. There was also a significant association between knee/ ankle pain and LBP. Compared with the participants without knee/ankle pain, the adjusted ORs (95\% CI) for LBP were $4.25(2.55-7.07)$ for the participants with knee pain and $3.79(2.26-6.36)$ in the participants with ankle pain (Table 2).

\section{Discussion}

Our main finding was that lower extremity pain was associated with LBP in young basketball players. Further, both knee and ankle pain were associated with LBP among the young basketball players.

Although reports of LBP among young basketball players are rare, one study showed a $37.9 \%$ lifetime prevalence of LBP among school-aged basketball players [18]. Another report showed a lifetime prevalence of $45.4 \%$ and a one-week prevalence of $19.8 \%$ among young basketball players with a mean age of 14.9 years [5]. Further, our study showed that the point prevalence of LBP among school-aged basketball players was $12.8 \%$.
Because basketball players are considered to have a high prevalence of LBP, even young players, elucidating the related factors, and identifying effective prevention and treatment methods for LBP among young basketball players is necessary.

Although there are only a few reports, the association between lower extremity pain and LBP or back pain has been demonstrated in other sports, such as baseball and football $[15,17]$. The lower extremities provide a stable base for lumbar movement [19] and control the ground reaction forces to the lower back [12]. Lower extremity pain can interrupt these processes and may transfer excessive loads to the lumbar spine, which can lead to LBP. Overall, $36.4 \%$ of players had lower extremity pain in our study. Players are required to repeat sudden stops, turns, jumps, and landings in basketball [5] and thus have a high frequency of lower extremity injuries [20]. Further, $25.8 \%$ of players with lower extremity pain had LBP, which was significantly higher compared with $5.3 \%$ of players without lower extremity pain. Longitudinal studies should be conducted to clarify the association of preceding lower extremity pain with LBP, which may provide useful information to clinicians and coaches to treat and prevent LBP among young basketball players.

Considering the types of lower extremity pain, some authors have reported that the knee is the most commonly injured body part in basketball players [20, 21]. During basketball movements, players often keep their knees bent [4] and knee pain can disrupt this function. Insufficient knee flexion upon landing reduces shock absorption and increases vertical forces to the low back [22]. In our study, $25.2 \%$ of young basketball players

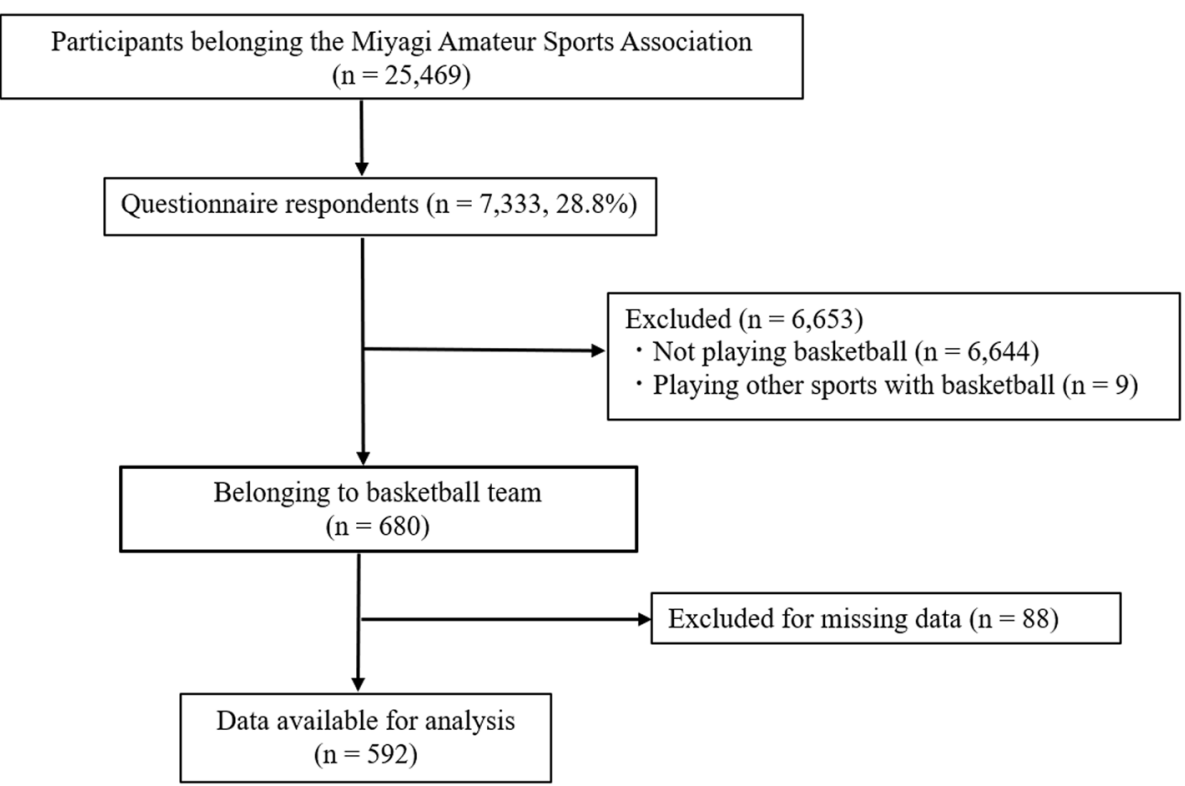

Fig. 1 Flow chart of the study design 
Table 1 Baseline characteristics of the participants

\begin{tabular}{|c|c|c|c|c|}
\hline Variables & Categories & Median (IQR) & Total, N (\%) & Low back pain, N (\%) \\
\hline Total & & & 592 & 76 \\
\hline \multirow[t]{2}{*}{ Gender } & Male & & $332(56.1)$ & $35(46.1)$ \\
\hline & Female & & $260(43.9)$ & $41(53.9)$ \\
\hline Age (years) & & $13.0(12.0,14.0)$ & & \\
\hline Body mass index & & $18.3(16.7,19.8)$ & & \\
\hline \multirow[t]{4}{*}{ Team levels } & Recreation & & $30(5.1)$ & $2(2.6)$ \\
\hline & Local competition & & $376(63.5)$ & $49(64.5)$ \\
\hline & Prefectural competition & & $169(28.5)$ & $22(28.9)$ \\
\hline & Tohoku district or national competition & & $17(2.9)$ & $3(3.9)$ \\
\hline Training per week (days) & & $5.0(3.5,6.0)$ & & \\
\hline Practice per day weekdays (hours) & & $2.0(2.0,2.5)$ & & \\
\hline Practice per day weekends (hours) & & $3.0(3.0,4.0)$ & & \\
\hline \multirow[t]{4}{*}{ Frequency of participation in games } & never & & $31(5.2)$ & $3(3.9)$ \\
\hline & seldom & & $57(9.6)$ & $7(9.2)$ \\
\hline & sometimes & & $175(29.6)$ & $21(27.6)$ \\
\hline & often & & $329(55.6)$ & $45(59.2)$ \\
\hline \multirow[t]{2}{*}{ Practice intensity } & Low-to-medium & & $203(34.3)$ & $18(23.7)$ \\
\hline & High & & $389(65.7)$ & $58(76.3)$ \\
\hline
\end{tabular}

reported knee pain. Among those, 26.8\% had LBP, which was significantly higher compared with $8.1 \%$ among players without knee pain. This result suggests that knee pain increases the load on the low back and leads to LBP in young basketball players. Suter et al. (2001) showed the association between diminished knee extensor strength and LBP in their cross-sectional study [23].

Table 2 Association of lower extremity pain with low back pain among young basketball players

\begin{tabular}{|c|c|c|c|}
\hline & \multicolumn{3}{|l|}{ Lower extremity pain } \\
\hline & Absence $(n=375)$ & Presence $(n=217)$ & $p$ value \\
\hline Low back pain, n (\%) & $20(5.3)$ & $56(25.8)$ & \\
\hline Crude ORs (95\% Cl) & 1 & $6.17(3.59-10.63)$ & $<0.001$ \\
\hline \multirow[t]{3}{*}{ Adjusted ORs (95\% Cl) } & 1 & $6.26(3.60-10.89)$ & $<0.001$ \\
\hline & \multicolumn{3}{|l|}{ Knee pain } \\
\hline & Absence $(n=443)$ & Presence $(n=149)$ & $p$ value \\
\hline Low back pain, n (\%) & $36(8.1)$ & $40(26.8)$ & \\
\hline Crude ORs (95\% Cl) & 1 & $4.15(2.52-6.82)$ & $<0.001$ \\
\hline \multirow[t]{3}{*}{ Adjusted ORs (95\% Cl) } & 1 & $4.26(2.55-7.10)$ & $<0.001$ \\
\hline & \multicolumn{3}{|l|}{ Ankle pain } \\
\hline & Absence $(n=465)$ & Presence $(n=127)$ & $p$ value \\
\hline Low back pain, n (\%) & $41(8.8)$ & $35(27.6)$ & \\
\hline Crude ORs $(95 \% \mathrm{Cl})$ & 1 & $3.93(2.38-6.51)$ & $<0.001$ \\
\hline Adjusted ORs (95\% Cl) & 1 & $3.92(2.33-6.61)$ & $<0.001$ \\
\hline
\end{tabular}

Knee pain reduces knee extension strength and disrupts knee function, which results in an increased load on the low back. These hypotheses should be assessed in future studies, which may provide an effective approach to treat and prevent LBP in young basketball players.

Ankle injuries are also common among basketball players [6]. In basketball, ankle sprains are major injuries that are often caused by jumps or landings, because it is common to play in areas with high player concentrations [20]. Ankle sprains also have high re-injury rates among basketball players [21] and can lead to a high prevalence of ankle pain. Brantingham et al. (2006) reported that decreased range of motion of the ankle was associated with LBP, which was due to the loss of shock absorption at the ankle [24]. In our study, the prevalence of ankle pain was $21.5 \%$. Among those with ankle pain, 27.6\% had LBP, which was significantly higher compared with $8.8 \%$ of players without ankle pain. Preceding ankle pain can be associated with the onset of LBP, which should be assessed in future longitudinal studies. Although only a few studies have reported on the associations of ankle function with LBP [25], the results of our study provide an insight into the association of disrupted ankle function with LBP onset. Further research to investigate this association can aid in the development of a strategy for the treatment and prevention of LBP among young basketball players.

This study has several limitations. First, we distributed the questionnaires by mail. As a result, the response rate was not high. Furthermore, the sample size was not 
calculated at the start of this study because the number of respondents could not be predetermined. Second, low back and lower extremity pain were assessed using a self-reported questionnaire, but the intensity and duration of pain were not assessed. Additionally, the reliability and validity of this questionnaire were not evaluated in this study. Questionnaires specific to low back and lower extremity pain should be considered in future studies. Finally, this study employed a crosssectional design and there remained the possibility of reverse causality.

\section{Conclusion}

Elementary and middle school-aged basketball players with lower extremity pain have a high prevalence of LBP. Further research is needed to clarify the mechanism of this association, which will give useful information for prevention and treatment of LBP among young basketball players.

\section{Supplementary information}

Supplementary information accompanies this paper at https://doi.org/10. 1186/s13102-020-00189-6.

\section{Additional file 1}

\section{Abbreviations}

BMI: Body mass index; Cl: Confidence interval; LBP: Low back pain; OR: Odds ratio

\section{Acknowledgements}

This study was performed as part of the Miyagi Sports Medical Projects and was supported by Asahi Breweries (Asahi Group Holdings, Ltd).

\section{Authors' contributions}

YY, YH, and RN designed the study. HM, MT, KK, NI, SY, YS, TY, and TO collected the data and supervised the study. TS and $Y Y$ conducted statistical analysis. YY, YH, and El wrote the manuscript. YS, MT, and TI helped to analyse the data and draft the manuscript. All authors have read and approved the manuscript.

\section{Funding}

This work was supported by Asahi Soft Drink Co., Ltd. for collecting the data.

\section{Availability of data and materials}

The datasets used and/or analysed during the current study are available from the corresponding author on reasonable request.

\section{Ethics approval and consent to participate}

The study protocol was reviewed and approved by the Ethics Committee on Research of Human Subjects at Tohoku University Graduate School of Medicine (approval number: 2013-1-564). All participants gave informed consent to participate in this study. Parental/guardian consent was also obtained because the participants were younger than 16 years of age. Written informed consent was obtained from all the participants and parents/guardians

\section{Consent for publication}

Not applicable.

\section{Competing interests}

The authors declare no potential conflicts of interest.

\section{Author details}

'Department of Orthopaedic Surgery, Tohoku University School of Medicine, 1-1 Seiryo-machi, Aoba-ku, Sendai 980-8574, Japan. ${ }^{2}$ Department of Medicine and Science in Sports and Exercise, Tohoku University School of Medicine, 2-1 Seiryo-machi, Aoba-ku, Sendai 980-8575, Japan. ${ }^{3}$ Department of Nursing, Faculty of Health Science, Tohoku Fukushi University, 1-8-1 Kunimi, Aoba-ku, Sendai 981-8522, Japan. ${ }^{4}$ Division of Biomedical Engineering for Health and Welfare, Tohoku University Graduate School of Biomedical Engineering, 2-1 Seiryo-machi, Aoba-ku, Sendai 980-8575, Japan.

Received: 29 February 2020 Accepted: 30 June 2020

Published online: 06 July 2020

References

1. Hangai M, Kaneoka K, Okubo Y, Miyakawa S, Hinotsu S, Mukai N, Sakane M, Ochiai N. Relationship between low back pain and competitive sports activities during youth. Am J Sports Med. 2010;38(4):791-6.

2. Takemitsu M, El Rassi G, Woratanarat P, Shah SA. Low back pain in pediatric athletes with unilateral tracer uptake at the pars interarticularis on single photon emission computed tomography. Spine (Phila Pa 1976). 2006;31(8): 909-14.

3. Farahbakhsh F, Akbari-Fakhrabadi M, Shariat A, Cleland JA, Farahbakhsh F, Seif-Barghi T, Mansournia MA, Rostami M, Kordi R. Neck pain and low back pain in relation to functional disability in different sport activities. J Exerc Rehabil. 2018;14(3):509-15.

4. Rossi MK, Pasanen K, Heinonen A, Myklebust G, Kannus P, Kujala UM, Tokola K, Parkkari J. Incidence and risk factors for back pain in young floorball and basketball players: a prospective study. Scand J Med Sci Sports. 2018;28(11): 2407-15.

5. Pasanen K, Rossi M, Parkkari J, Kannus P, Heinonen A, Tokola K, Myklebust G. Low back pain in young basketball and floorball players. Clin J Sport Med. 2016;26(5):376-80.

6. Cumps E, Verhagen E, Meeusen R. Prospective epidemiological study of basketball injuries during one competitive season: ankle sprains and overuse knee injuries. J Sports Sci Med. 2007;6(2):204-11.

7. Noormohammadpour P, Rostami M, Mansournia MA, Farahbakhsh F, Pourgharib Shahi MH, Kordi R. Low back pain status of female university students in relation to different sport activities. Eur Spine J. 2016;25(4):1196-203.

8. Fett D, Trompeter K, Platen P. Back pain in elite sports: a cross-sectional study on 1114 athletes. PLoS One. 2017;12(6):e0180130.

9. Shah T, Cloke DJ, Rushton S, Shirley MD, Deehan DJ. Lower back symptoms in adolescent soccer players: predictors of functional recovery. Orthop J Sports Med. 2014;2(4):2325967114529703.

10. Jonasson P, Halldin K, Karlsson J, Thoreson O, Hvannberg J, Sward L, Baranto A. Prevalence of joint-related pain in the extremities and spine in five groups of top athletes. Knee Surg Sports Traumatol Arthrosc. 2011;19(9):1540-6.

11. Sekiguchi T, Hagiwara Y, Momma H, Tsuchiya M, Kuroki K, Kanazawa K, Yabe Y, Koide M, Itaya N, Itoi E, et al. Youth baseball players with elbow and shoulder pain have both low back and knee pain: a cross-sectional study. Knee Surg Sports Traumatol Arthrosc. 2016;26(7):1927-35.

12. Nadler SF, Wu KD, Galski T, Feinberg JH. Low back pain in college athletes a prospective study correlating lower extremity overuse or acquired ligamentous laxity with low back pain. Spine (Phila Pa 1976). 1998;23(7): 828-33.

13. Young JL, Herring SA, Press JM, Casazza BA. The influence of the spine on the shoulder in the throwing athlete. J Back Musculoskelet Rehabil. 1996; 7(1):5-17.

14. Yabe $Y$, Hagiwara $Y$, Sekiguchi T, Momma H, Tsuchiya M, Kuroki K, Kanazawa K, Koide M, Itaya N, Itoi E, et al. Late bedtimes, short sleeping time, and longtime video-game playing are associated with low back pain in schoolaged athletes. Eur Spine J. 2018;27(5):1112-8.

15. Sogi Y, Hagiwara Y, Yabe Y, Sekiguchi T, Momma H, Tsuchiya M, Kuroki K, Kanazawa K, Koide M, Itaya N, et al. Association between trunk pain and lower extremity pain among youth soccer players: a cross-sectional study. BMC Sports Sci Med Rehabil. 2018;10:13.

16. Sekiguchi T, Hagiwara Y, Momma H, Tsuchiya M, Kuroki K, Kanazawa K, Yabe Y, Yoshida S, Koide M, Itaya N, et al. Coexistence of trunk or lower extremity pain with elbow and/or shoulder pain among young overhead athletes: a cross-sectional study. Tohoku J Exp Med. 2017;243(3):173-8.

17. Yabe $Y$, Hagiwara $Y$, Sekiguchi $T$, Momma H, Tsuchiya $M$, Kuroki $K$, Kanazawa K, Koide M, Itaya N, Yoshida S, et al. Knee pain is associated with lower back 
pain in young baseball players: a cross-sectional study. Knee Surg Sports Traumatol Arthrosc. 2019;27(3):985-90.

18. Sato T, Ito T, Hirano T, Morita O, Kikuchi R, Endo N, Tanabe N. Low back pain in childhood and adolescence: assessment of sports activities. Eur Spine J. 2011;20(1):94-9.

19. Seroyer ST, Nho SJ, Bach BR, Bush-Joseph CA, Nicholson GP, Romeo AA. The kinetic chain in overhand pitching: its potential role for performance enhancement and injury prevention. Sports Health. 2010;2(2):135-46.

20. Meeuwisse WH, Sellmer R, Hagel BE. Rates and risks of injury during intercollegiate basketball. Am J Sports Med. 2003;31(3):379-85.

21. Riva D, Bianchi R, Rocca F, Mamo C. Proprioceptive training and injury prevention in a professional men's basketball team: a six-year prospective study. J Strength Cond Res. 2016;30(2):461-75.

22. Muller R, Ertelt T, Blickhan R. Low back pain affects trunk as well as lower limb movements during walking and running. J Biomech. 2015;48(6):1009-14

23. Suter E, Lindsay D. Back muscle fatigability is associated with knee extensor inhibition in subjects with low back pain. Spine (Phila Pa 1976). 2001:26(16):E361-6.

24. Brantingham JW, Lee Gilbert J, Shaik J, Globe G. Sagittal plane blockage of the foot, ankle and hallux and foot alignment-prevalence and association with low back pain. J Chiropr Med. 2006;5(4):123-7.

25. McClinton S, Weber CF, Heiderscheit B. Low back pain and disability in individuals with plantar heel pain. Foot (Edinb). 2018;34:18-22.

\section{Publisher's Note}

Springer Nature remains neutral with regard to jurisdictional claims in published maps and institutional affiliations.

Ready to submit your research? Choose BMC and benefit from:

- fast, convenient online submission

- thorough peer review by experienced researchers in your field

- rapid publication on acceptance

- support for research data, including large and complex data types

- gold Open Access which fosters wider collaboration and increased citations

- maximum visibility for your research: over $100 \mathrm{M}$ website views per year

At BMC, research is always in progress.

Learn more biomedcentral.com/submissions 